\title{
ETHE1 overexpression promotes SIRT1 and PGC1a mediated aerobic glycolysis, oxidative phosphorylation, mitochondrial biogenesis and colorectal cancer
}

\author{
Mavee Witherspoon ${ }^{1 *}$, Davinder Sandu ${ }^{2 *}$, Changyuan Lu ${ }^{2}$, Kehui Wang ${ }^{3}$, Robert \\ Edwards $^{3}$, Anthony Yeung ${ }^{4}$, Ozkan Gelincik ${ }^{1}$, Giovanni Manfredi ${ }^{5}$, Steven Gross $^{2}$ \\ Levy Kopelovich ${ }^{1 * *}$ and Steven Lipkin \\ ${ }^{1}$ Department of Medicine, Weill Cornell College of Medicine, New York, NY, USA \\ ${ }^{2}$ Department of Pharmacology, Weill Cornell College of Medicine, New York, NY, USA \\ ${ }^{3}$ Department of Pathology and Laboratory Medicine, University of Irvine School of Medicine, Irvine, CA, USA \\ ${ }^{4}$ Fox Chase Cancer Center, Philadelphia, PA, USA \\ ${ }^{5}$ Department of Neurology, Weill Cornell College of Medicine, New York, NY, USA \\ *These authors have contributed equally to this work \\ *** Jointly led the study \\ Correspondence to: Steven Lipkin, email: st12012@med.cornell.edu \\ Levy Kopelovich, email: kopelovichl@gmail.com \\ Keywords: familial adenomatous polyposis; ethylmalonic encephalopathy 1; mitochondrial bioenergetics; aerobic glycolysis; \\ colorectal cancer \\ Received: January 16, $2018 \quad$ Accepted: April 21, $2019 \quad$ Published: June 18, 2019 \\ Copyright: Witherspoon et al. This is an open-access article distributed under the terms of the Creative Commons Attribution \\ License (CC BY 3.0), which permits unrestricted use, distribution, and reproduction in any medium, provided the original author \\ and source are credited
}

\section{ABSTRACT}

Ethylmalonic Encephalopathy Protein 1 (ETHE1) is a sulfur dioxygenase that regulates cellular $\mathrm{H}_{2} \mathrm{~S}$ levels. We previously demonstrated a significant increase of ETHE1 expression in "single-hit" colon epithelial cells from crypts of patients with Familial Adenomatous Polyposis (FAP). Here, we report elevated levels of ETHE1 expression and increased mitochondrial density occurring in-situ in phenotypically normal FAP colorectal mucosa. We also found that constitutive expression of ETHE1 increased aerobic glycolysis ("Warburg effect"), oxidative phosphorylation, and mitochondrial biogenesis in colorectal cancer (CRC) cell lines, thereby depleting $\mathrm{H}_{2} \mathrm{~S}$ which relieved the inhibition of phosphodiesterase (PDE), and increased adenosine monophosphate (AMP) levels. This led to activation of the energy sensing AMPactivated protein kinase (AMPKp), Sirtuin1 (SIRT1) and peroxisome proliferatoractivated receptor $Y$ coactivator 1a (PGC1a), a master regulator of mitochondrial biogenesis. By contrast, shRNA silencing of ETHE1 reduced PDE activity, AMPKP/ SIRT1/PGC1a levels and mitochondrial biogenesis. Constitutive expression of ETHE1 accelerated both CRC cell xenograft and orthotopic patient derived xenograft CRC cell growth in vivo. Overall, our data nominate elevated ETHE1 expression levels as a novel biomarker and potential therapeutic target for the prevention of CRC tumorigenesis.

\section{INTRODUCTION}

The discovery of tumor suppressor genes (TSGs) and their singular role in the etiology of heritable cancers presents the opportunity to study early biomarkers and potential targets during cancer progression [1]. Previously, we investigated gene expression patterns of phenotypically normal "one-hit" cells before they become hemizygous or 
homozygous for the inherited mutant TSG that promotes tumor formation in hereditary cancers. This approach enables discovery of biomarkers and molecular targets in clinically-identifiable pre-neoplastic lesions such as polyposis of the colon, wherein numerous lesions appear before progression to adenocarcinomas [1-4].

Familial Adenomatous Polyposis (FAP) is characterized by hundreds to thousands of adenomatous polyps throughout the colorectum $[5,6]$. The majority of FAP patients carry a germline mutation in the adenomatous polyposis coli (APC) tumor suppressor, a negative regulator of WNT signaling and regulator of cell proliferation [7]. The high rate of somatic APC mutations in sporadic colorectal cancer is consistent with inactivation of the APC protein playing a critical role in the initiation of colorectal cancers [8]. This highlights the need to improve our understanding of events that occur during the transition of normal colon mucosa to cancer including development of early biomarkers and potential targets to prevent/treat FAP and other cohorts at high risk of CRC [9-15].

A recent proteomic study showed that phenotypically normal epithelial cells from the colonic crypts of FAP patients, referred to as "one-hit" cells, when compared to normal colon epithelial cells, revealed a significant increase ( 27-fold) of the Ethylmalonic encephalopathy protein 1 (ETHE1) which, represented the highest increase in expression among all proteins identified [16]. ETHE1 is a sulfur dioxygenase, a hydrogen sulfide $\left(\mathrm{H}_{2} \mathrm{~S}\right)$ catabolic enzyme, that is widely expressed in various tissues and is present in the mitochondria, cytosol and nucleus of eukaryotic animals [17]. In the mitochondria, ETHE1 facilitates $\mathrm{H}_{2} \mathrm{~S}$ catabolism via oxidation and conversion of sulfide quinone reductase generated glutathione persulfides (GSSH) to sulfite $\left(\mathrm{H}_{2} \mathrm{SO}_{3}\right)[18,19]$. Sulfite is further oxidized to sulfate that is secreted extra-cellularly. Consistent with this role, germline bi-allelic ETHE1 mutations cause ethylmalonic encephalopathy[20-23], a genetic disease in which $\mathrm{H}_{2} \mathrm{~S}$ accumulates in critical tissues and can reach concentrations in the brain that inhibit Cytochrome C Oxidase (COX), blocking mitochondrial respiration, increasing lactic acid accumulation, and inducing encephalopathy $[22,24,25]$. Here, we focused on the colon since ETHE1 is highly expressed in normal colorectal epithelium wherein it modulates the accumulation of toxic endogenous $\mathrm{H}_{2} \mathrm{~S}$ generated by colonic microbiota, dietary sulfur containing compounds and endogenous cellular $\mathrm{H}_{2} \mathrm{~S}$ produced by cystathionine beta-synthase (CBS) [19, 26].

We found abnormal expression of ETHE1 and increased mitochondria density in phenotypically normal $\mathrm{APC}^{+/}$FAP intact colorectal mucosa. Furthermore, using constitutively expressed ETHE1 in CRC cells we identified novel mechanisms that link augmented ETHE1 expression with aerobic glycolysis and mitochondria biogenesis. We found that constitutive expression of ETHE1 reduces $\mathrm{H}_{2} \mathrm{~S}$ mediated inactivation of phosphodiesterases
(PDEs) and increases AMP concurrent with increased AMPK phosphorylation. This in turn activates the NAD-dependent protein deacetylase Sirtuin 1 (SIRT1). AMPK and Sirt1 are key metabolic sensors that regulate mitochondrial respiration and aerobic glycolysis [27-31]. AMPK and SIRT1 directly activate the nuclear receptor Peroxisome Proliferator-Activated Receptor Gamma Coactivator 1 Alpha (PGC1 $\alpha$ ) through phosphorylation (AMPK) and deacetylation (SIRT1), respectively [32-34]. PGC1 $\alpha$ then drives mitochondrial biogenesis and oxidative phosphorylation leading to increased CRC proliferation, angiogenesis, and tumor growth in vivo.

Overall our studies provide new insights into the mechanistic role of elevated ETHE1 expression levels during CRC tumorigenesis in phenotypically normal "one-hit" FAP colon, highlighting the utility of the "onehit" model in heritable cancers to facilitate the discovery of potential biomarkers/targets, early during CRC progression.

\section{RESULTS}

\section{In situ expression of ETHE1 in intact colon mucosa tissue specimens of FAP patients}

Yeung et al. demonstrated that phenotypically normal, non-transformed APC "single-hit" cells in FAP epithelium showed the highest differential increase in ETHE1 levels among all proteins identified compared to normal colon epithelial cells from control subjects [16]. We further validated these findings using phenotypically normal intact colon mucosa surgical specimens from FAP $(\mathrm{N}=3)$ patients carrying APC c.388delA, APC c.1240delC and APC c.2586insCA truncating mutations, and individuals with no history of $\mathrm{CRC}(\mathrm{N}=3)$ who were matched for location (sigmoid colon) age, gender and ethnicity, collected during screening colonoscopy. Western blot analysis confirmed $>160 \%(\mathrm{p}=0.001$ unpaired $\mathrm{t}$-test $)$ increase in ETHE1 protein levels in FAP colonic tissues (Figure 1A and 1B).

\section{ETHE1 expression and activity in CRC cell lines}

To study the role of increased ETHE1 levels in CRC, we used human-derived HCT116 and HT29 CRC cell lines that stably constitutively expresses a full-length cDNA encoding ETHE1. Concurrently, gene specific shorthairpin RNA (shRNA) sequences were used to knockdown ETHE1 in these cell lines. Western blot (Figure $1 \mathrm{C}$ and $1 \mathrm{D}$ ) and densitometry analysis (Figure 1E and $1 \mathrm{~F}$ ) confirmed increased ETHE1 protein levels ( $\mathrm{p}=0.001$ unpaired t-test) in constitutively expressed HCT116 and HT29 (Figure 1E and 1F) cells.

Next, we tested whether ETHE1 was enzymatically active in CRC cells. ETHE1 facilitates $\mathrm{H}_{2} \mathrm{~S}$ catabolism via oxidation of sulfide quinone reductase generated glutathione persulfides (GSSH) 
to sulfite $\left(\mathrm{H}_{2} \mathrm{SO}_{3}\right)$, in a reaction that requires oxygen and water. Sulfite is further oxidized to sulfate and secreted. Several studies have shown that GSSH is the main substrate for ETHE1[35-38]. Therefore, we mixed freshly prepared $735 \mu \mathrm{M}$ glutathione persulfide (GSSH) with $200 \mu \mathrm{g}$ cell lysate under air-saturated conditions at $\mathrm{pH} 7.4$ and measured the disappearance rate of GSSH using an established monobromobimane (MBB) method with LC/MS [35]. In both ETHE1 overexpressing CRC cell lines, metabolism of GSSH was increased compared to ETHE1 scrambled control cell lysates (HT29-CE $p=0.0001$; HCT116-CE $p=0.007$ ) (Figure 1G). Conversely, ETHE1 knockdown CRC cells showed reduced rates of GSSH consumption relative to controls. Thus, ETHE1 actively reduces $\mathrm{H}_{2} \mathrm{~S}$ metabolites in $\mathrm{CRC}$ cell lines.

\section{ETHE1 protein levels correlate with FAP mitochondrial protein enrichment}

We performed a re-analysis of 214 differentially expressed two-dimensional gel protein spots identified in morphologically normal, "single-hit" FAP and low CRC risk colon epithelial cells datasets [16]. Using this approach, we identified 66 non-redundant proteins with a threshold of $>1.5 \mathrm{X}$ up-regulation $(\mathrm{p}<0.01)$ in the "single-hit" FAP cells. The annotation cluster with the highest enrichment (enrichment score 14.95) for ETHE1 upregulation in these cells was identified as
"Mitochondrial proteins" (Supplementary Table 1). This subset of upregulated proteomic annotation cluster categories included mitochondrial transit peptide containing proteins $(\mathrm{p}=1.62 \mathrm{E}-15)$, mitochondrial lumen and matrix proteins $(\mathrm{p}=7.63 \mathrm{E}-15)$, as well as envelope (outer membrane) and mitochondrial inner membrane proteins (Supplementary Table 1).

To test further mitochondrial involvement, we compared the ultrastructural characteristic of phenotypically normal, intact FAP colon tissue specimens, with matched colon tissues from control individuals by transmission electron microscopy (EM). Phenotypically normal FAP colon epithelial biopsies showed densely distributed mitochondria throughout the cytoplasm and increased mitochondrial matrix staining, when compared to intact colon controls (Figure 2A and 2B). Next, we examined CRC cell lines with different ETHE1 expression levels for their ultrastructural features. Similar to intact FAP colon biopsies, ultrastructural analysis of constitutively expressing ETHE1 HCT116 (Figure 2C and 2D) and HT29 cells (Figure 2F and $2 \mathrm{G})$ showed increased mitochondrial matrix staining. In contrast, silencing of ETHE1 reduced mitochondrial matrix density in HCT116 (Figure 2E) and HT29 (Figure $2 \mathrm{H})$ cells, compared with scrambled controls. Overall, we show a strong correlation between elevated ETHE1 levels and increased mitochondrial density and matrix in histologically normal colonic epithelia from FAP patients and in CRC cells.
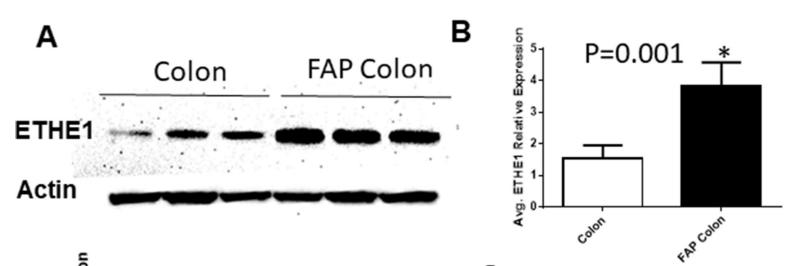

E
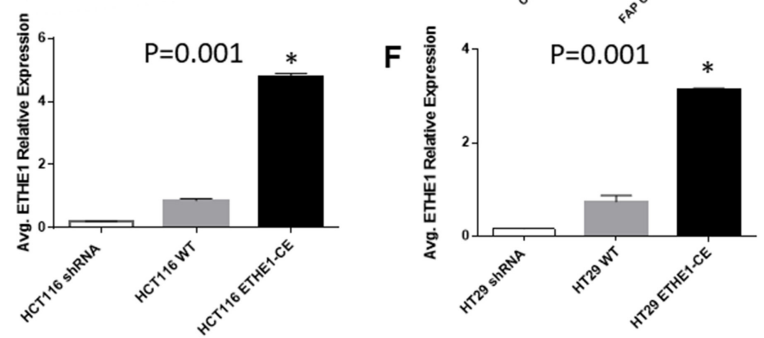
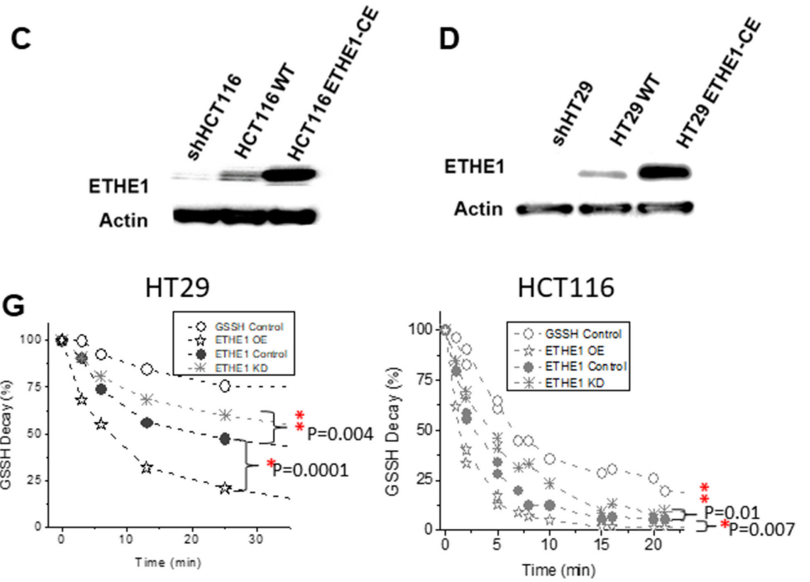

Figure 1: Increased ETHE1 expression and Activity in FAP and CRC. Total protein extracts from FAP and colon biopsy (A) (20ug protein per sample) were subjected to immunoblotting with anti-ETHE1 (1:500 Abgent) or anti-Actin( 1:10000 Abcam). (B) Avg. relative expression of FAP ETHE1 by densitometry of Western blots( 1 way ANOVA, $\mathrm{N}=3, \mathrm{p}=0.001$ ). Whole cell lysates from shRNA knockdown, scrambled control(WT) or lentiviral (genecopoeia) generated ETHE1 constitutive expressing (CE) CRC cell lines HCT116(C) and (D) HT29. Avg. relative expression of ETHE1 CRC variants (E) HCT116 and (F) HT29 by densitometry of Western blots ; ( $\mathrm{p}=0.001$ unpaired t-test). (G) Kinetic analysis of ETHE1 catabolism of GSSH in HT29 and HCT116 ETHE1-CE lysate. To determine ETHE1 activity, whole cell lysates were incubated with glutathione persulfide (GSSH), ETHE1 increases the rate of $\mathrm{O}_{2}$ dependent consumption of glutathione persulfides (GSSH). ${ }^{*}$-values $<0.01$. 


\section{ETHE1 upregulates oxidative phosphorylation in CRC}

Since the mitochondrial matrix plays a critical role to convert energy derived from oxidation/ reduction reactions of electron transport, we examined the expression levels of key mitochondrial oxidative phosphorylation (OXPHOS) related proteins in whole cell homogenates that were derived from phenotypically normal biopsied tissue specimens of FAP patients and control individuals. Phenotypically normal FAP patient lysates exhibited increased ( $\mathrm{P}=0.001$; 1-way ANOVA) levels of ATP synthase (ATPase) subunits, succinate dehydrogenase $(S D B H)$, cytochrome c reductase $(\mathrm{QH} 2)$, cytochrome c oxidase $(\mathrm{COX})$ and ubiquinone oxidoreductase (NADH) (Figure 2I) protein levels as compared with low CRC risk controls. Previous studies have shown higher COXI expression in CRC cells than in normal colon epithelia, indicating a role for increased cytochrome $\mathrm{c}$ oxidase $(C O X)$ expression in the transformation of colon epithelia [39]. Consistent with these reports, densitometric analysis of FAP vs sporadic western blot data, showed a $\sim 15$ fold increase in $C O X$ expression (paired t-test, $\mathrm{p}=0.001$ ) in the phenotypically normal intact FAP colon biopsies (Figure 2K).

To investigate whether ETHE1 levels were directly associated with this subset of mitochondrial protein expression, we probed constitutively expressing ETHE1 CRC cell lines for OXPHOS levels. Analysis of ETHE1 CRC cell homogenates showed that constitutive upregulation of ETHE1 in HCT116 and HT29 cells increased OXPHOS protein levels (Figure $2 \mathrm{~J})$. Densitometric analysis revealed that upregulation of ETHE1 in HCT116 (Figure 2L) and HT29 (Figure $2 \mathrm{M})$ significantly increased $(>2 \mathrm{x}, \mathrm{p}=0.001)$ expression of COXI, SDBH and NADH. This effect was attenuated by shRNA-mediated silencing of ETHE1 CRC cells, resulting in approximately a $3 \mathrm{x}$ to $10 \mathrm{x}$ fold reduction $(\mathrm{P}<0.05)$ of COXI expression in HT29 and HCT116 (Figure $2 \mathrm{~L}$ and $2 \mathrm{M}$ ), respectively. Taken together, these results are consistent with a direct role of ETHE1 to drive mitochondrial OXPHOS protein expression and mitochondrial content.
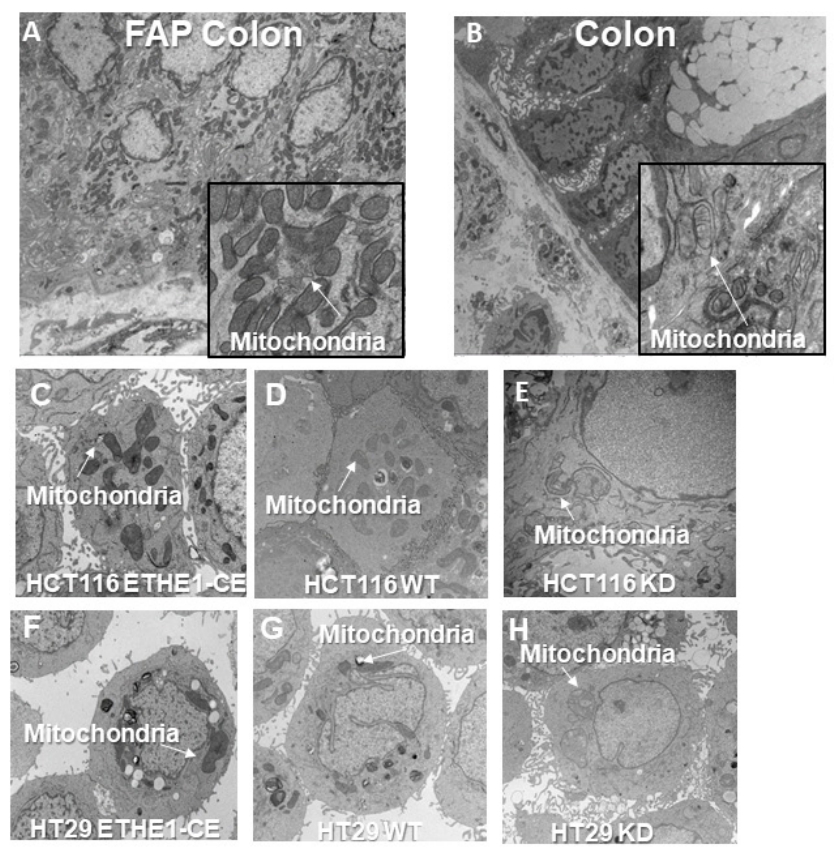
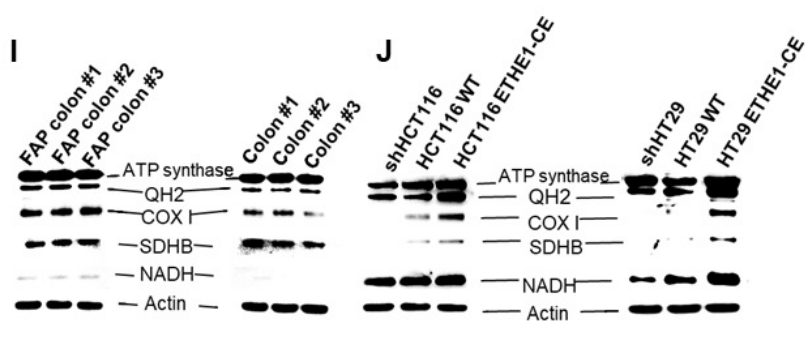

K
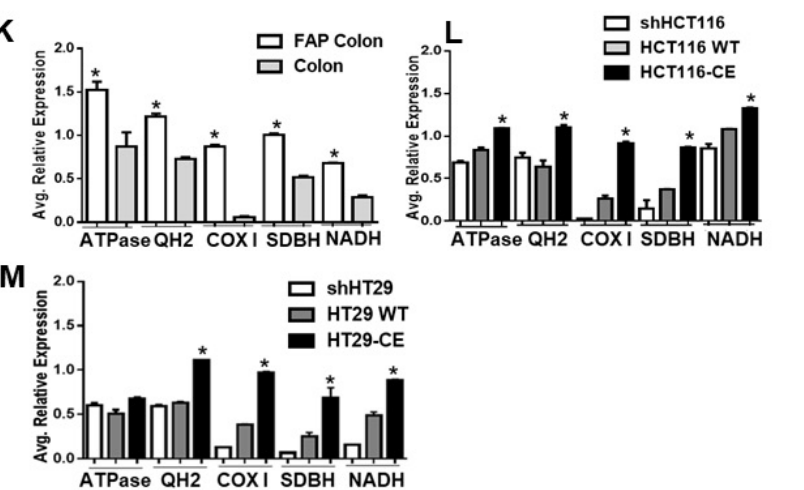

Figure 2: ETHE1 promotes expression of CRC mitochondrial oxidative phosphorylation proteins. Representative electron micrographs of biopsied patient mucosa, shows increased mitochondrial matrix density in (A) intact FAP colon vs (B) intact colon ( $\mathrm{n}=3$ ). Constitutive expression of ETHE1 in CRC cells HCT116(C), HT29 (F) displays increased mitochondrial matrix density verses scrambled controls $(\mathbf{D}, \mathbf{G})$. A decrease in mitochondrial matrix density was observed in ETHE1 shRNA knockdownHCT116 (E) and (H) HT29 CRC cells. Original magnification; 8000x to 50,000x, Arrows indicate mitochondria. Analysis of 20 images per group. ${ }^{*}$ Two-sided Paired t-test $\mathrm{p}<0.001$. Total protein extracts from FAP colon and colon biopsy (20ug/samples) (I), ETHE1 overexpressing HCT116 and HT29 (J) probed for mitochondrial OXPHOS proteins (MitoProfile Total OXPHOS; abcam). Avg relative OXPHOS protein expression of FAP colon vs (K) colon, ETHE1 CRC variants HCT116 (L), HT29 (M) determined by densitometry of Western blots; (1way ANOVA,N=3,p=0.002). 


\section{Overexpression of ETHE1 enhances CRC mitochondrial respiration and aerobic glycolysis}

Our results showed that phenotypically normal, FAP colon biopsies and CRC cell lines contained large numbers of mitochondria with increased mitochondrial matrix staining, consistent with metabolically highly active mitochondria. To investigate the role of elevated ETHE1 levels as a driver of mitochondrial respiration, we used the Seahorse XF96 extracellular flux analyzer on CRC cells with elevated, normal and knocked-down levels of ETHE1. Using this approach, we generated mitochondrial bioenergetics profiles from HCT116 (Figure 3A) and HT29 (Figure 3B) cells. Constitutive expression of ETHE1 significantly increased HCT116 basal respiration ( 51\%), ATP turnover $(\sim 57.5 \%)$, spare respiratory capacity $(\sim 113 \%)$ and maximal respiration $(\sim 67.7 \%)$ (Figure $3 \mathrm{C}$ $3 \mathrm{~F})$ compared with scrambled parental control cells. It also increased HT29 basal respiration ( 84\%), ATP turnover $(\sim 93.9 \%)$, maximal respiration $(\sim 88.1 \%)$ and spare respiratory capacity ( $\sim 95.5 \%)$ (Figure $3 \mathrm{G}-3 \mathrm{~J})$. Notably, all CRC cell lines, regardless of ETHE1 expression levels demonstrated a positive association between increased oxygen consumption rate (OCR) and extra-cellular acidity rate (ECR), indicating the concurrent occurrence of enhanced mitochondrial respiration and aerobic glycolysis ("Warburg effect") (Figures 3K and 3L). Yet this association appeared to trend most clearly in the case of constitutively enriched ETHE1 cell lines (Figures $3 \mathrm{~K}$ and 3L). In this context, shRNA silencing of ETHE1 reduced basal respiration, ATP turnover, spare respiration capacity, and maximal respiration. Altogether, our data demonstrate that upregulation of ETHE1 increased not only protein levels of key mitochondrial oxidative phosphorylation related proteins, but has also contributed to metabolic adaptations associated with tumor malignancies wherein both aerobic glycolysis and respiratory capacity are implicated[40].

\section{ETHE1 regulates the SIRT1/PGC1 $\alpha$ axis}

The mechanisms responsible for the regulation of mitochondrial biogenesis and function involve complex networks of transcriptional factors and cofactors. The Sirtuin (Sirt) family of deacetylases activates mitochondriogenic cellular programs and increased aerobic glycolysis $[28,30,32,41]$. Sirtuin1 (SIRT1) is a well characterized NAD dependent type III nuclear deacetylase. SIRT1 transcriptionally regulates the peroxisome proliferator-activated receptor $\gamma$ coactivator $1 \alpha(P G C 1 \alpha)[29,30,32,33]$, an important regulator of mitochondrial biogenesis and function [33, 42].

First, we therefore determined SIRT1 and PGC1 $\alpha$ protein levels in cell homogenates from phenotypically normal, intact FAP colon tissue biopsies. SIRT1 and its target $P G C 1 \alpha$ protein levels were significantly increased in FAP colon verses normal colon controls (Figure 4A). Next, we determined PGC1 expression in HCT116 and HT29 scrambled shRNA control cells (Figure 4B). We then examined constitutively expressing ETHE1 HCT116 (Figure 4C) and HT29 (Figure 4D) cells to test whether SIRT1 and PGC1 $\alpha$ levels were directly regulated by ETHE1. Similar to intact FAP tissue biopsies, SIRT1 and PGC1 $\alpha$ were upregulated in constitutively expressed ETHE1 cell lines. In contrast, shRNA silencing of ETHE1 reduced both PGC1 $\alpha$ and SIRT1 protein levels in CRC cells.

In addition, we determined SIRT1 deacetylase activity in high and low ETHE1 expressing CRC cells. We prepared nuclear extracts from constitutively expressing ETHE1 HCT116 and HT29 cells using a SIRT1 activity assay kit (Figure 4E). The results showed that, consistent with increased SIRT1 levels, SIRT1 functional deacetylase activity was also upregulated in high ETHE1 expressing HCT116 and HT29 cells. In contrast, shRNA silencing of ETHE1 reduced SIRT1 activity (Figure 4E). Thus, ETHE1 levels can positively drive SIRT activity.

\section{PDE mediated stimulation of pAMPK/SIRT1 is linked to ETHE1 levels}

$\mathrm{H}_{2} \mathrm{~S}$ inhibits phosphodiesterase activity, affecting the rate of c-AMP conversion to AMP [34, 43, 44]. Building upon our findings that overexpression of ETHE1 increased the rate of GSSH catabolism in CRC cell lysates (Figure 1G), we then determined whether $\mathrm{H}_{2} \mathrm{~S}$ levels can alter phosphodiesterase activity. We first measured the levels of total GSSH in constitutively expressing ETHE1 HCT116 and HT29 using the GSSGGlo assay. Consistent with increased ETHE1 -mediated $\mathrm{H}_{2} \mathrm{~S}$ catabolism, $\mathrm{H}_{2} \mathrm{~S}$ levels were decreased in high ETHE1 expressing HCT116 (Figure 5A) and HT29 (Figure 5B) cells, as determined by GSSG levels. In contrast, shRNAmediated silencing of ETHE1 CRC upregulated GSSH levels. Next, we determined PDE activity in high and low ETHE1 expressing cells using a cAMP-Glo assay. These results showed that cAMP levels were decreased in high ETHE1 expressing HCT116 (Figure 5C) and HT29 cells (Figure 5D), consistent with increased PDE activity and conversion of cAMP to AMP.

To study the mechanism through which ETHE1 decrease of $\mathrm{H}_{2} \mathrm{~S}$ promotes the AMPK/SIRT1 axis, including increased mitochondrial biogenesis and function, we used a Cystathionine- $\beta$-synthase (CBS) inhibitor, aminooxyacetic acid (AOAA). CBS is a $\mathrm{H}_{2} \mathrm{~S}$ producing enzyme, shown to be overexpressed in CRC cells $[26,45]$. We, therefore, prepared total cell extracts from constitutively expressing ETHE1 HCT116 and HT29 cells treated with AOAA (1-10mM) and measured AMPKp and SIRT1 protein levels. We found that inhibition of CBS activity resulted in increased AMPKp, SIRT1 and PGC1 $\alpha$ 
expression in these cells (Figure 5E-5H). Overall, these results are consistent with increased ETHE1 catabolism of endogenous $\mathrm{H}_{2} \mathrm{~S}$, leading to increased PDE activity and AMPKp/SIRT1 expression. Since Cystathionine- $\beta$ synthase (CBS) is an important contributor to intracellular $\mathrm{H}_{2} \mathrm{~S}$ production (24), we also examined whether low or high ETHE1 levels altered CBS expression in CRC cells. Western blot analysis showed that changes in ETHE1 levels had no effect on CBS expression in HT29 (Supplementary Figure 1A) or HCT116 cells (Supplementary Figure 1B). Therefore, increased ETHE1 levels do not appear to notably affect the CBS pathway.

\section{ETHE1 stimulates oncogenesis of CRC cells in vitro and in vivo}

Increased expression of SIRT1 and PGC1 $\alpha$ increase cell proliferation and angiogenesis [46, 47]. Since ETHE1 upregulated SIRT1 and PGC1 $\alpha$, we tested whether cell proliferation was affected by ETHE1 expression levels using BrdU incorporation assays. The results show that high expressing ETHE1 HCT116 (Figure 6A) and HT29
(Figure 6B) cells exhibit increased cell proliferation in vitro.

Next, we performed xenograft studies to test the effects of increased ETHE1 expression on angiogenesis. Male NOD/Scid mice were injected in either flank (S.C) with constitutively expressing ETHE1 HT29/HCT116 or scrambled control cells. The percentage of KI67 positive tumor cell nuclei was counted in $4 \times$ random images (magnification 20x) (Figure 6C, 6D). The results show that, in contrast to scrambled controls, high ETHE1 expression significantly increased HT29 and HCT116 $\mathrm{Ki}^{+}(122-194 \%)$ staining (Figure 6E and 6F). In addition, we found that high ETHE1 expression significantly increased the number of vascular endothelial CD31+ cells (Figure 6G and $6 \mathrm{H}$ ) in xenograft tumors by $>2$ fold. Taken together, these data are consistent with a role for ETHE1 to increase not only CRC cell proliferation, aerobic glycolysis and OxPhos, but also angiogenesis in vivo.

To assay the effects of high ETHE1 expression on $\mathrm{CRC}$ tumorigenicity, we injected (via lateral tail vein) male non-obese diabetic/severe combined immunodeficient (NOD/SCID) mice with constitutively expressing ETHE1 HCT116 $\left(1 \times 10^{6}\right)$ or HT29 $\left(1 \times 10^{6}\right)$ cells. High ETHE1
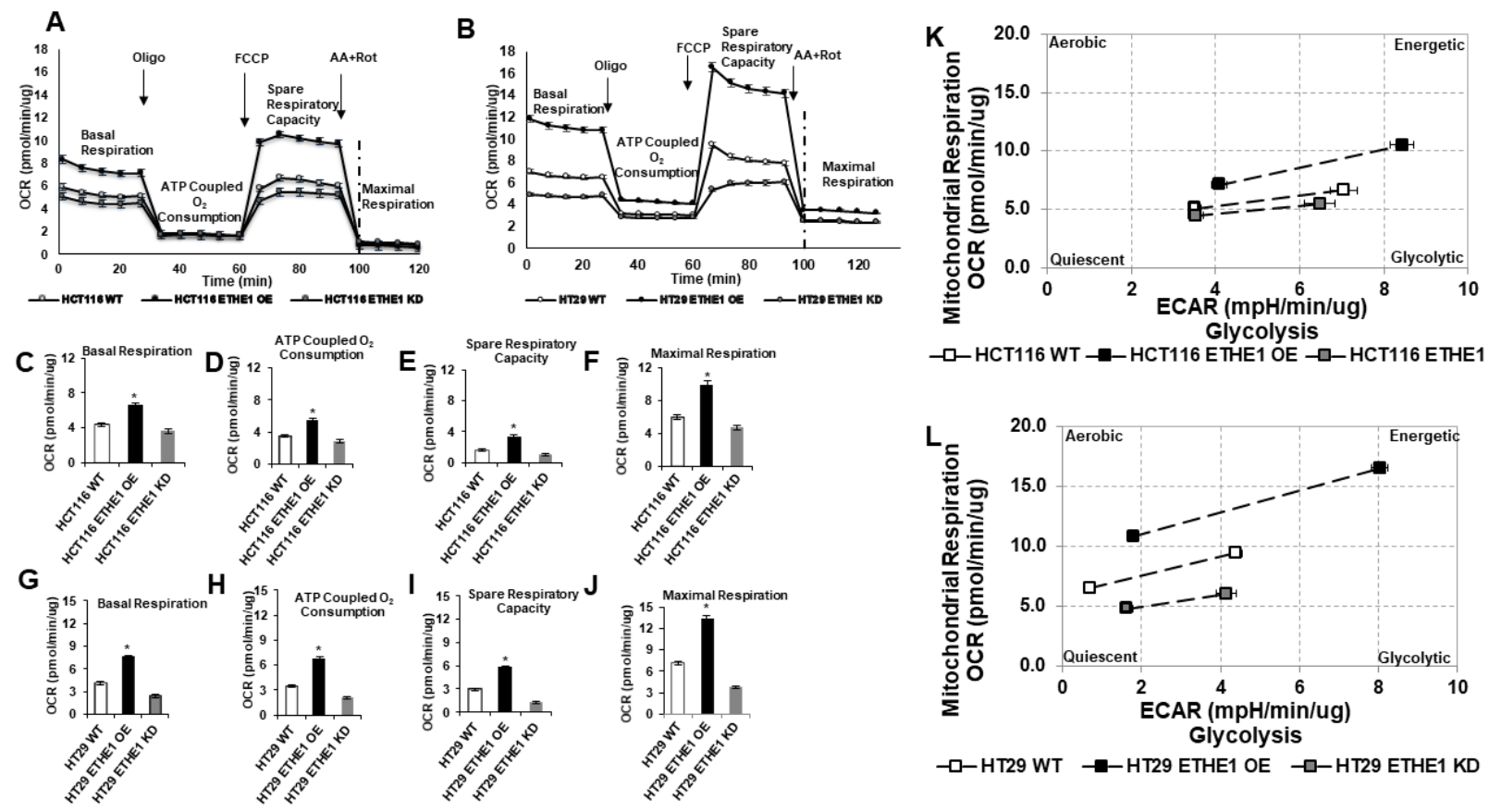

Figure 3: Overexpression of ETHE1 enhances CRC mitochondrial respiration. Oxygen Consumption rate (OCR) in shRNA knockdown or lentiviral ETHE1 constitutive expressing (CE) CRC cell lines (A) HCT116 and (B) HT29. Constitutive expression of ETHE1 significantly increased, whereas silencing of ETHE1 reduced HCT116 and HT29 basal OCR (C, G), ATP Coupled O 2 Consumption $(\mathbf{D}, \mathbf{H})$, spare respiratory capacity $(\mathbf{E}, \mathbf{I})$ and maximal respiration $(\mathbf{F}, \mathbf{J}) .{ }^{*} \mathrm{P}<0.05$ or ${ }^{* *} \mathrm{P}<0.01 \mathrm{vs}$. wt control. Data represent mean $\pm \mathrm{SEM}$ of $n=4$. two-sided Student's t test. OCR determined by; Basal respiration (rate before first injection - non-mitochondrial respiration rate), ATP Coupled $\mathrm{O}_{2}$ Consumption (rate before oligomycin injection - rate after oligomycin injection), Maximal Respiration (rate after FCCPnon-mitochondrial respiration rate), Spare Respiratory Capacity (Maximal Respiration - Basal respiration). ETHE1 constitutive expression in (K) HCT116 and HT29 (L) CRC cells show an increased glycolytic response under stress (oligomycin). 
expression increased intestinal and extra-colonic HCT116 and HT29 tumor multiplicity and tumor size (4x fold) compared with scrambled control parental cells (Figure 6I6L). Importantly, mice injected (via lateral tail vein) with high expressing ETHE1 HCT116 or HT29 cells showed reduced overall survival (Figure $6 \mathrm{M}$ and $6 \mathrm{~N}$ ). These results are consistent with ETHE1 levels as a mechanistic driver of colorectal cancer growth in vivo.

\section{DISCUSSION}

Previous studies have shown that germline ETHE1 mutations in ethylmalonic encephalopathy lead to an accumulation of $\mathrm{H}_{2} \mathrm{~S}$ and inhibition of Cytochrome $\mathrm{C}$ Oxidase (COX) which is essential for mitochondrial respiration, affecting severe dysfunction in cellular energy metabolism [18, 48, 49]. While the effects of ETHE1 deficiency have been thoroughly investigated, the consequences of increased ETHE1 expression in CRC tumorigenesis are poorly understood. In hepatocellular carcinoma (HCC), ETHE1 is overexpressed [50], where it is associated with inhibition of caspase 9 activation, suppressing DNA-damage induced apoptosis by binding to the RelA p65 subunit of NFkB, and increasing its export from the nucleus [50]. However, in our initial studies we did not see activation of this pathway in phenotypically normal intact colon mucosa from FAP patients (cancer initiation), indicating that increased ETHE1 expression involves different mechanisms in different cancer types.

Similar to previous proteomic studies on "singlehit" FAP/APC normal colon epithelial cells [16], our data show a significant increase in $\mathrm{f}$ ETHE 1 expression in phenotypically normal intact mucosa tissue from FAP patients, including an associated increase in mitochondrial content/matrix, as compared with normal colon mucosa from control subjects. The impact of ETHE1 overexpression in early in situ CRC tumorigenesis on mitochondrial proteins was further illustrated through re-analysis of differentially expressed two-dimensional gel protein spots identified in phenotypically normal, "single-hit" FAP epithelial cells[16]. Using this approach, we identified 66 non-redundant proteins in "single-hit"FAP epithelial cells in which the annotation cluster with the highest enrichment (enrichment score
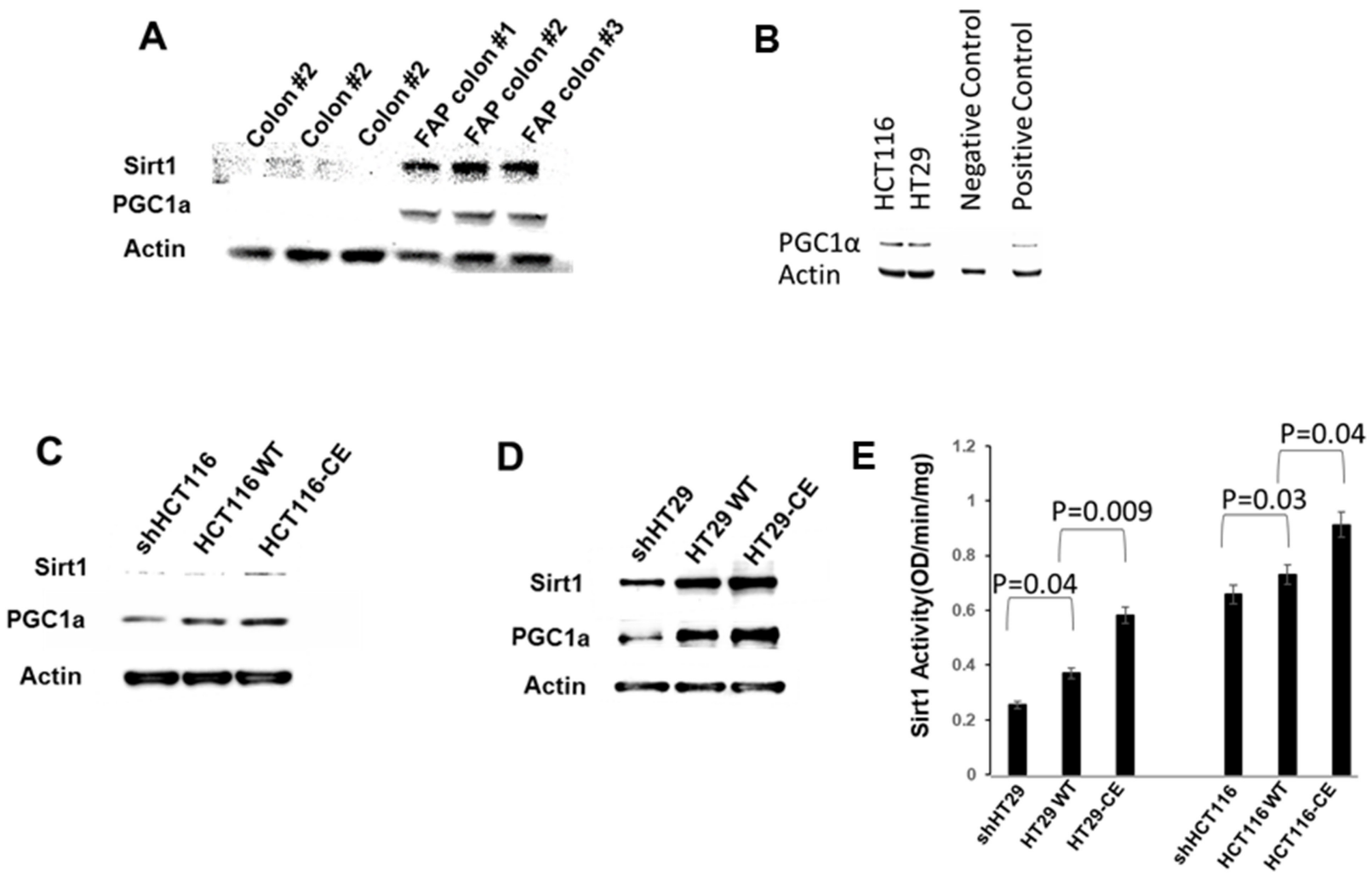

Figure 4: ETHE1 regulates the Sirt1/PGC1 $\alpha$ axis. (A) Total protein extracts from FAP colon and colon biopsy (20ug/samples) (B) Total protein extracts from HCT116 or HT29 shRNA controls, probed for PGC1a (abcam 1:1000). Positive and negative control lysates included (Novus biologicals). (C) ETHE1 overexpressing HCT116 and (D) HT29 CRC cells showed increased SIRT1 and PGC1 $\alpha$ protein levels compared with scrambled and shRNA controls (Abcam 1:500 Sirt1, Abcam 1:1000 PGC1 $\alpha$ ). (E) ETHE1 overexpressing HT29 and HCT116 CRC cells (5ug of nuclear extract/sample) shows increased Sirt1 activity (Abcam). N=3, Statistics; Paired t-test. Two-sided. 
14.95) in these cells was identified as "Mitochondrial proteins" (Supplementary Table 1), attesting to the strong correlation between elevated ETHE1 levels and increased mitochondrial proteins in "single-hit" FAP cells. These data are consistent with our current observations regarding ETHE1 over expression and increased mitochondrial biogenesis seen in phenotypically normal FAP mucosa specimens occurring in situ.

Accordingly, we investigated the metabolic impact of ETHE1 expression in CRC cell lines at baseline and after knockdown or constitutive overexpression. Increased ETHE1 expression in CRC cells stimulated mitochondrial biogenesis/bioenergetics and increased mitochondrial matrix staining, consistent with an overall increased mitochondrial activity. Thus, constitutively upregulated ETHE1 in CRC cells share phenotypic similarities with alterations seen in FAP patient normal mucosa epithelium in situ. By contrast, mitochondrial matrix, OXPHOS protein expression and respiration levels were reduced following shRNA silencing of ETHE1 in CRC cells. These data are consistent with a novel mechanistic role for
ETHE1 function in which, in addition to $\mathrm{H}_{2} \mathrm{~S}$ catabolism, if abnormally expressed, it promotes mitochondrial biogenesis and cellular respiration.

Mitochondria are key metabolic and biosynthetic regulators that are intimately involved in cancer cell growth. SIRT1, AMPK and PGC1 $\alpha$ are important regulators of mitochondrial biogenesis. The NAD+ dependent deacetylase SIRT1 and AMPK have been shown to upregulate PGC1 $\alpha$ activity $[27,29,31,32,43]$. Thus, our data point to a basic pathway that underlies ETHE1 overexpression in CRC cells. Our data support a process whereby increased $\mathrm{H}_{2} \mathrm{~S}$ catabolism lowers $\mathrm{H}_{2} \mathrm{~S}$ levels, which increases PDE activity. This leads to increased AMP, which promotes phosphorylation of AMPK, leading AMPKp and SIRT1 directly to stimulate PGC1 $\alpha$. Together, AMPKp and SIRT1 increase PGC1 $\alpha$ and promote CRC mitochondrial biogenesis and respiration, including aerobic glycolysis (the "Warburg hypothesis") (Figure 7). In fact cellular respiration and aerobic glycolysis have been shown to occur concurrently in many tumors, and although aerobic glycolysis is
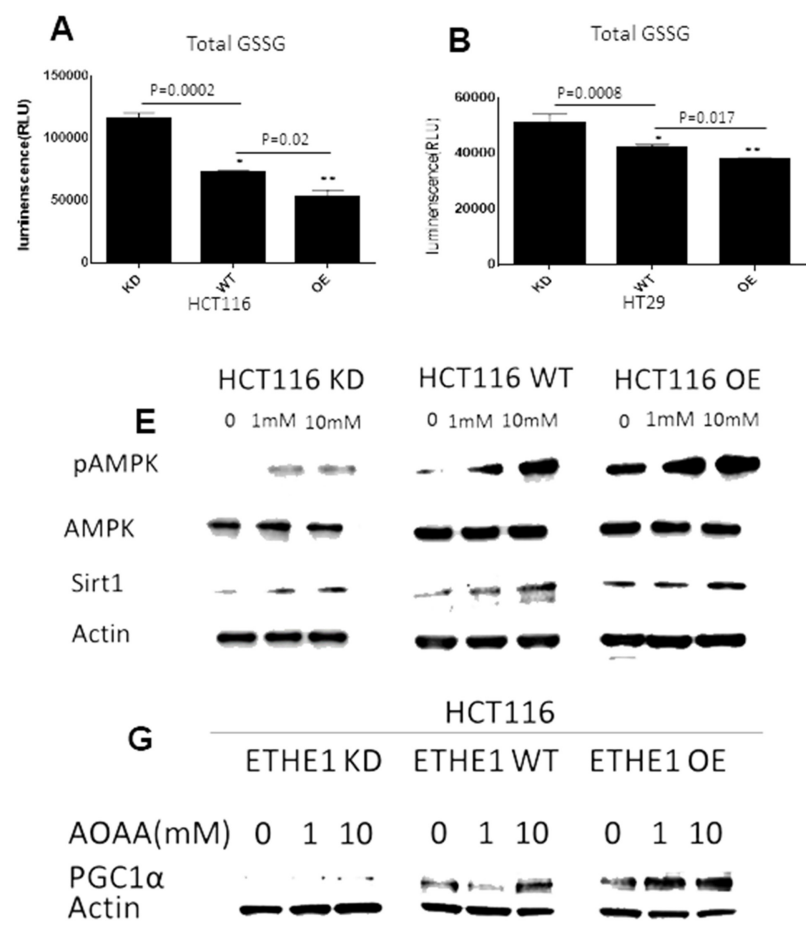
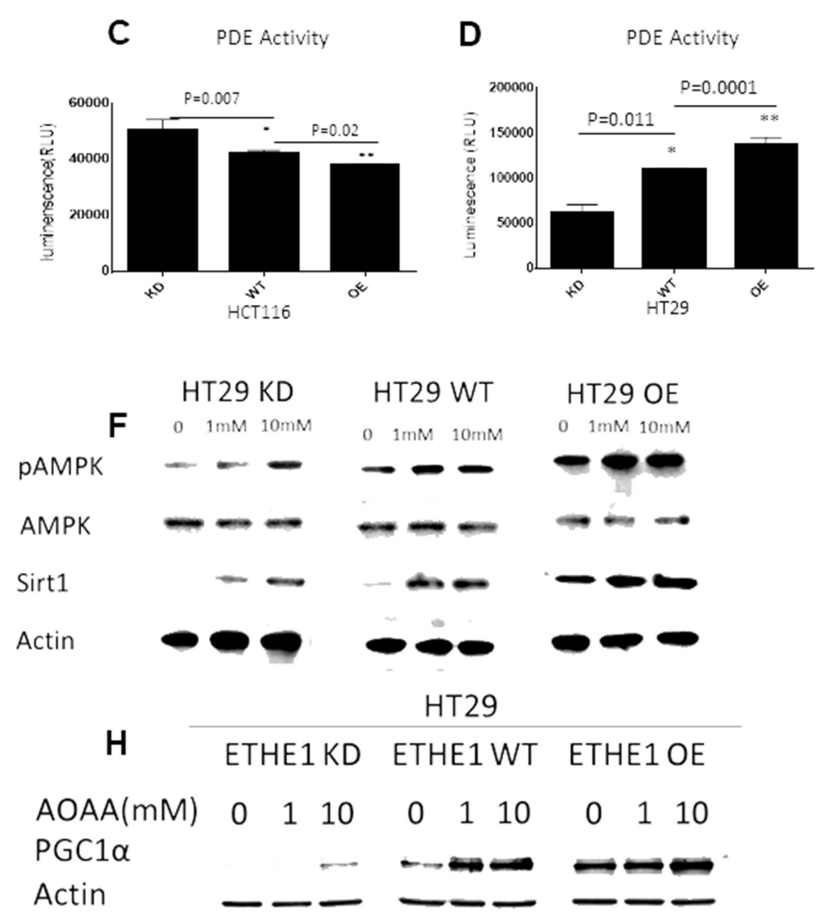

Figure 5: ETHE1 levels drive PDE mediated stimulation of pAMPK/Sirt1. Cells were seeded (30K) in 96 well plates, HCT116 (A) and HT29 (B) cells expressing low (KD), scrambled control (WT) or high ETHE1 (OE) were used to measure $\mathrm{H}_{2} \mathrm{~S}$, as determined by GSSG levels (GSH/GSSG Promega), ETHE1 high expressing cells showed reduced GSSG, suggesting reduced $\mathrm{H}_{2} \mathrm{~S}$ levels. shRNA silencing of ETHE1 showed increased GSSH levels; N=3; unpaired T-test. PDE activity determined by cAMP-Glo Assay (Promega), (cAMP levels are inversely proportional to luminescence); HCT116 (C) and HT29 (D) ETHE1 overexpressing cells (seeded $30 \mathrm{~K}$ in 96 well plates) show reduced cAMP levels (high luminescence), suggesting increased PDE activity, shRNA silencing of ETHE1 increased cAMP levels, as compared with wild type control. N=3; unpaired T-test. Total protein extracts from HCT116 (E) and HT29 (F) CRC cells treated with the CBS inhibitor aminooxyacetic acid (AOAA), showed increased activation of AMPK (pAMPK) and Sirt1 expression. PGC1 $\alpha$ levels in HCT116(G) and HT29(H) ETHE1 ${ }^{\mathrm{KD} / \mathrm{WT} / \mathrm{OE}}$ CRC cells treated with AOAA. 


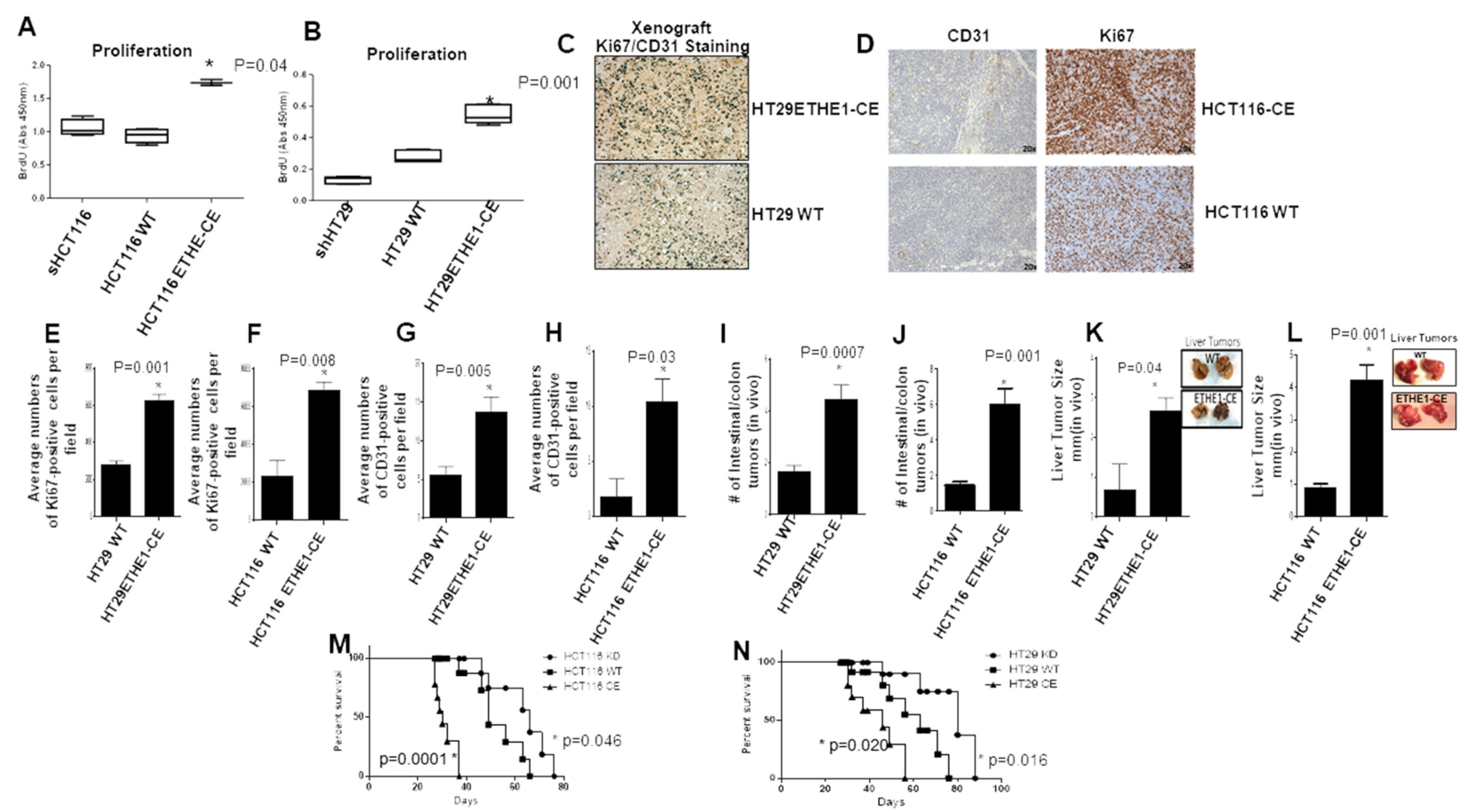

Figure 6: ETHE1 stimulates CRC tumorgenicity in vivo. (A) HCT116 and (B) HT29 CRC cell proliferation, 50K cells plated. Cells were incubated with BrdU (BrdU cell proliferation assay, Cell Signaling). N=3. Abs 450. two-sided Student's t test. (C and D) HT29/ HCT116 CD31/Ki67 staining of xenografts (CD31, Ki67 Cell signaling), shRNA controls were used. Quantification of Ki67/CD31 positive cells HT2 $9^{\text {shRNAwt } / C E}$ and HCT11 $6^{\text {shRNAwt/CE }}(\mathbf{E}-\mathrm{H})$ showed increased staining in ETHE1 high expressing xenografts, 20x magnification images $(\mathrm{N}=3)$ analyzed using ImageJ software, Statistics; Paired t-test. Two-sided. Tail vein injection of CRC cells into NOD/SCID mice showed increased intestinal/colon tumor numbers ( $\mathbf{I}$ and $\mathbf{J})$ and extracolonic $(\mathbf{K}$ and $\mathbf{L})$ tumor size was determined $(\mathrm{N}=8)$. Reduce survival in NOD/SCID mice injected with ETHE1 expressing (M) HCT116 $6^{\text {ETHEI-CEE }}$ (N) HT2 $9^{\text {ETHEl-CE }}$ cells. Increased survival in mice injected with HCT116 ${ }^{\text {ETHE1-KD }}$ or HT29 ${ }^{\text {ETHE1-KD }}$ (log rank test) (N=8; mice per group).

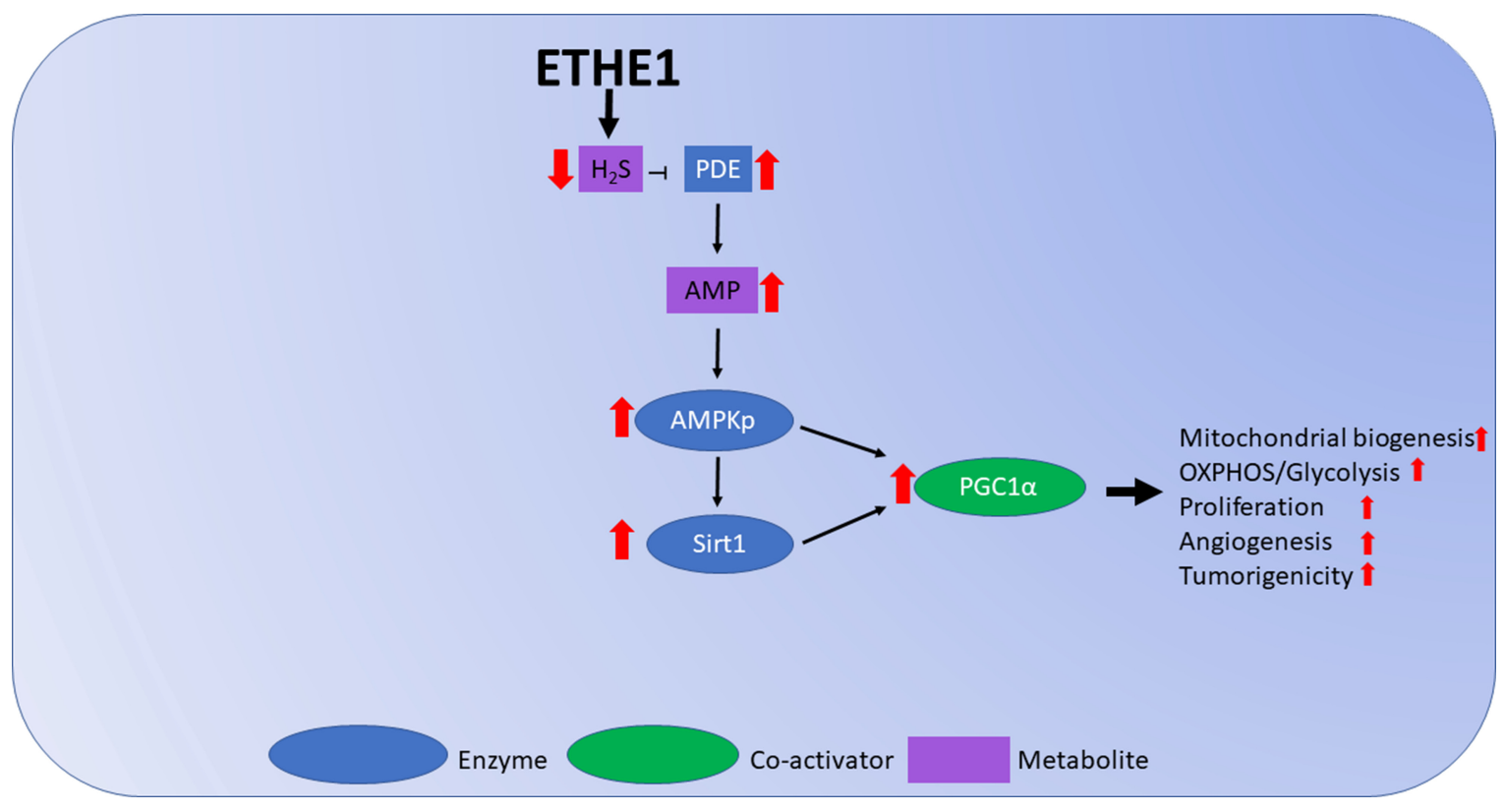

Figure 7: Model figure of ETHE1 roles in FAP. Overexpression of ETHE1 prevents $\mathrm{H}_{2} \mathrm{~S}$ mediated inhibition of PDE, increasing AMPKp activation of Sirt 1 and subsequent induction of $\mathrm{PGC} 1 \alpha$, increasing CRC mitochondrial OXPHOS, proliferation, angiogenesis and tumorigenicity. 
an inefficient way to generate ATP, most cancer cells depend on it [40]. Supporting this notion are recent studies showing that proliferating cells require metabolic pathways that incorporate nutrients into biomass, and that cancer-associated mutations enable cancer cells to support proliferation rather than efficient ATP production $[40,51$ 53]. We showed a positive association between increased aerobic glycolysis and cell respiration that is further impacted by ETHE1. Thus, ETHE1 alters the metabolism of cancer cells in order to facilitate increased biomass and cell growth, increased cellular respiration notwithstanding.

Concordant with our results in vitro, in vivo studies showed that constitutive expression of ETHE1 in CRC cells increased $\mathrm{KI} 67^{+} / \mathrm{CD} 31^{+}$staining in NOD/SCID xenograft mouse models. Additionally, mice injected (via lateral tail vein) with constitutively expressing ETHE1 HCT116 $\left(1 \times 10^{6}\right)$ or HT29 $\left(1 \times 10^{6}\right)$ cells show reduced median survival time, increased tumor incidence, tumor burden, multiplicity and metastasis in vivo. Significantly, ETHE1 null (KO) CRC cells showed much reduced tumor cell growth and increased median survival time in vivo compared to WT or ETHE1 overexpressing CRC cells. These data provide evidence that upregulation of ETHE1 plays an important role in driving pathogenesis of CRC in vivo.

Previously, ETHE1 protein levels were shown to be elevated in FAP normal colonic mucosa (15). Our findings here confirm these original findings in additional FAP colon biospecimens and extend our current mechanistic understanding of the role of ETHE1 in FAP CRC tumorigenesis with both in vitro and in vivo studies, leading to the following salient conclusions: First, because ETHE1 promotes CRC cell growth, and is upregulated in phenotypically normal $\mathrm{APC}^{+/}$FAP colon epithelium, high ETHE1 levels may be useful as an early biomarker of CRC premalignant risk. Second, ETHE1 may be a potential chemoprevention target for FAP and high-risk sporadic CRC patients. Third, there has been a significant amount of interest regarding the potential influence of gastrointestinal microbiota on CRC tumorigenesis (50-54). Specifically, microbial species associated with CRC risk include fusobacteria, a genus of anaerobic gram-negative bacteria, and in particular fusobacterium nucleatum which produces $\mathrm{H}_{2} \mathrm{~S}$ [54-58]. Thus, paracrine $\mathrm{H}_{2} \mathrm{~S}$ production by colonic epithelium adherent Fusobacteria nucleatum driving ETHE1 upregulation may constitute an additional mechanism of CRC tumorigenesis for this important bacterium.

\section{MATERIALS AND METHODS}

\section{Cell culture}

Cells (HCT116, HT29) were maintained in Dulbecco's Modified Eagle Medium (DMEM; Invitrogen Corporation, Carlsbad, CA), 10\% fetal bovine serum
(Hyclone Laboratories, Inc., Logan, UT), $5 \mu \mathrm{g} / \mathrm{ml}$ gentamicin (Life Technologies, Gaithersburg, MD), and $0.75 \mu \mathrm{g} / \mathrm{ml}$ fungizone antimycotic (Invitrogen Corporation; DMEM complete). All cell lines were incubated in a $95 \%$ air and $5 \% \mathrm{CO}_{2}$ humidified atmosphere at $37^{\circ} \mathrm{C}$, and the medium was replaced every $48 \mathrm{~h}$.

\section{ETHE1 overexpressing CRC lines}

Constitutive expression of ETHE1 in HT29 and HCT116 cells, shRNA knockdown and scrambled shRNA control cells were established using a Lentivector-based system according to the manufacturer's instructions (GeneCopoeia Inc., Rockville, MD, USA). For lentiviralmediated gene transfer, Lv-101 T298) expression vector and transfected into HEK293 cells for pseudoviral packaging. Supernatants were collected and purified viral particles were titered and used to infect cells.

\section{FAP tissue specimens}

Phenotypically normal sigmoid colonic epithelium from FAP patients matched patient age, gender and ethnicity (European ancestry) with patients having screening colonoscopy with no personal, first or second degree history of CRC were obtained from the New York Presbyterian Hospital Center for Advanced Digestive Care Biobank under an IRB approved protocol (0908010582).

\section{Western blotting and AOAA treatment}

For immunostaining, cells lysed in $(500 \mathrm{mM} \mathrm{NaCl}$, $50 \mathrm{mM}$ Tris- $\mathrm{HCl} \mathrm{pH} 7.5,0.5 \%$ Triton X-100, $1 \mathrm{mM}$ EDTA, and $1 \mu \mathrm{M}$ DTT), clarified by centrifugation. 30ug of lysates were loaded on $10 \%$ BisTris gels and transferred to PVDF. Membranes were incubated with primary antibody (Anti-ETHE1 sigma, Anti-OxPhos Santa Cruz, Anti-CBS Santa Cruz, Anti-PGC1 $\alpha$ Santa Cruz) overnight at $4{ }^{\circ} \mathrm{C}$ and secondary antibody for $1 \mathrm{~h}$ at $4{ }^{\circ} \mathrm{C}$. For AOAA studies, cells were exposed to $1 \mathrm{mM}-10 \mathrm{mM}$ AOAA for $1 \mathrm{hr}$. Lysates were collected in NP-40 lysis buffer (Boston Bioproducts) supplement with complete mini EDTA free protease inhibitor (Roche). Membranes were incubated with primary antibodies; AMPK, AMPKp, SIRT1 antibodies (Cell Signaling).

\section{Metabolic flux assay}

Cells seeded in triplicate in $100 \mu \mathrm{L}$ DMEM at a density of $1 \times 10^{4}$ /well in XF96 96-well cell culture plate (Seahorse Bioscience, North Billerica, MA) and incubated at $37^{\circ} \mathrm{C}$ for $24 \mathrm{hrs}$. The XF96 sensor cartridge (Seahorse Bioscience) was prepared by incubation of each sensor pair in $1 \mathrm{ml}$ of Seahorse Bioscience XF96 Calibrant pH 7.4 (Seahorse Bioscience) at $37^{\circ} \mathrm{C}$ without $\mathrm{CO}_{2}$ for 24 h. Prior to analysis, the medium was removed and the wells washed with $1 \mathrm{ml}$ of pre-warmed Seahorse DMEM 
supplemented with $5 \mathrm{mM}$ glucose. A final volume of 180 $\mu \mathrm{l}$ assay medium was added to each well and the plate incubated at $37^{\circ} \mathrm{C}$ without $\mathrm{CO}_{2}$ for $1 \mathrm{hr}$. Either $1.5 \mu \mathrm{M}$ carbonyl cyanide-p-trifluoromethoxyphenylhydrazone (FCCP), $5 \mu \mathrm{M}$ oligomycin (Sigma-Aldrich, St. Louis, $\mathrm{MO})$ or $5 \mu \mathrm{M}$ antimycin was added to injection ports of the XF96 sensor cartridge in assay medium, equilibrated at least $15 \mathrm{~min}$ prior to analysis at $37^{\circ} \mathrm{C}$ without $\mathrm{CO}_{2}$. The XF96 sensor cartridge was calibrated in the Seahorse XF96 analyzer (Seahorse Bioscience), which was pre-warmed to $37^{\circ} \mathrm{C}$. Following calibration, the cell culture plate was placed in the analyzer and the extracellular acidification rate (ECAR) and the oxygen consumption rates (OCR) were simultaneously measured via the following protocol: three cycles of mix ( $2 \mathrm{~min})$, delay ( $2 \mathrm{~min})$; seven cycles of measure (4 min), mix ( $2 \mathrm{~min})$, delay ( $2 \mathrm{~min})$; port $\mathrm{A}$ injection; six cycles of mix (2 min), delay ( $2 \mathrm{~min})$, measure (4 min). Post-drug injection values were normalized to respective basal value and expressed as either $\mathrm{mpH} /$ $\mathrm{min} / 10^{4}$ cells (ECAR) or pmoles $/ \mathrm{min} / 10^{4}$ cells (OCR).

\section{Animals}

All animal studies and procedures done in accordance with protocols approved by WCMC. NOD/ SCID mice purchased from Jackson Laboratory. CCIC 707 or $823\left(1 \times 10^{6}\right)$ injected directly into the tail vein of 7 to 9 -week-old male NOD/SCID mice. Tumor burden was quantified by manually counting nodules visible on the intestinal epithelia surface. 8 week-old NOD/SCID female mice were used for ETHE1 CRC variant xenograft studies.

\section{Fixation \& embedding for electron microscopy}

Cells were washed with serum-free media or appropriate buffer, fixed with modified Karmovsky's; 2.5\% glutaraldehyde, $4 \%$ parafomaldehye and $0.02 \%$ picric acid in $0.1 \mathrm{M}$ sodium caocdylate buffer at $\mathrm{pH} 7.2$. Secondary fixation in $1 \%$ osmium tetroxide, $1.5 \%$ potassium ferricyanide samples were dehydrated through a graded ethanol series, and embedded in an epon analog resin. Ultrathin sections were cut using a Leica UltractuS ultramicrotome (Leica, Vienna, Austria) Sections collected on copper grids and contrasted with lead citrate and viewed on a JEM 1400 electron microscope (JEOL, USA, Inc., Peabody, MA) operated at $120 \mathrm{kV}$. Images were recorded with a Veleta $2 \mathrm{~K}$ $\mathrm{x} 2 \mathrm{~K}$ digital camera (Olympus-SIS, Germany).

\section{Activity of ETHE1 in CRC lysates}

ETHE1 consumption of gluathione persulfide (GSSH) experiments were prepared according to reference (20).

\section{Q-TOF LC-MS and LC-MS/MS}

Mass Spectroscopy (MS) was performed as previously performed in [59]

\section{Proliferation assay}

Cells were seeded in 96 well clear plates at 50,000 cells/well. After $24 \mathrm{hrs}$ fresh cell culture media containing $1 \mathrm{x}$ Brdu solution (cell biosciences) was added to media. Cell number was determined by measuring absorption at 450nM.

\section{GSSG and CAMP Assay}

Cells were seeded in 96 well white plates 50,000 cells/well. After $24 \mathrm{hrs}$, cells are lysed to release cAMP or total GSSG (Promega). cAMP or GSSH was determined by Luminesce using a FLUOstar Omega Multi-Mode Microplate Reader with CCD-based Spectrometer.

\section{Proteomic and ingenuity pathway reanalysis}

Reanalysis of the 214 protein spots that were identified as changed in intensity in FAP compared with the control group with $\mathrm{p}<0.01$ and fold changes each $>$ half fold. The David Bioinformatics Gene Ontology at NIH is one of the best accepted software for this analysis. The UNIPROT_ACCESSION names of the up or down proteins in spreadsheet "up vs down in 214" were submitted as gene list to David Bioinformatics site (http://david.abcc.ncifcrf.gov/summary.jsp) for "functional annotation clustering" analysis, using the human genome as background. The software calculates how much of the data fits into each protein category, according to Gene Ontology (GO terms) or KEGG protein pathway database.

\section{Abbreviations}

ETHE1: ethylmalonic encephalopathy 1; ETHE1-CE: ETHE1 constitutive expression; CRC: colorectal cancer; CCIC: colon-cancer-initiating cells; NOD/SCID:non-obese diabetic/severe combined immunodeficient; EM: electron micrographs;

\section{Author contributions}

Anthony Yeung and Levy Kopelovich made the original discovery regarding ETHE1 overexpression in FAP, leading to this conceived work and subsequent submission. Mavee Witherspoon, Davinder Sandu and Changyuan $\mathrm{Lu}$ acquired data. All authors played an important role interpreting the results. Mavee Witherspoon, Steven Lipkin and Levy Kopelovich drafted the manuscript. Steven Lipkin planned the project as principal investigator. All authors approved the final version.

\section{ACKNOWLEDGMENTS}

The authors would like to thank Kehui Wang, Robert Edwards and Ozkan Gelincik for technical assistance. 


\section{CONFLICTS OF INTEREST}

No Author has any Conflict of Interest to Disclose.

\section{FUNDING}

We acknowledge NCI CN43302 for support. We would also like to thank the Matthew Bell Foundation for their support of this study.

\section{REFERENCES}

1. Knudson AG Jr. Heredity and human cancer. Am J Pathol. 1974; 77:77-84. [PubMed].

2. Kopelovich L, Shea-Herbert B. Heritable. one-hit events defining cancer prevention? Cell Cycle (Georgetown, Tex). 2013; 12:2553-2557. https://doi.org/10.4161/cc.25690 [PubMed].

3. Phatak A, Athar M, Crowell JA, Leffel D, Herbert BS, Bale AE, Kopelovich L. Global gene expression of histologically normal primary skin cells from BCNS subjects reveals "single-hit" effects that are influenced by rapamycin. Oncotarget. 2019; 10:1360-1387. https://doi.org/10.18632/ oncotarget.26640 [PubMed].

4. Fan M, Pfeffer SR, Lynch HT, Cassidy P, Leachman S, Pfeffer LM, Kopelovich L. Altered transcriptome signature of phenotypically normal skin fibroblasts heterozygous for CDKN2A in familial melanoma: relevance to early intervention. Oncotarget. 2013; 4:128-141. https://doi. org/10.18632/oncotarget.786 [PubMed].

5. Lipkin $\mathrm{M}$. The identification of individuals at high risk for large bowel cancer: an overview. Cancer. 1977; 40:2523-2530. https://doi.org/10.1002/1097-0142(197711)40:5+<2523::aidcncr2820400919>3.0.co;2-x. [PubMed].

6. Nakamura Y, Nishisho I, Kinzler KW, Vogelstein B, Miyoshi Y, Miki Y, Ando H, Horii A. Mutations of the APC (adenomatous polyposis coli) gene in FAP (familial polyposis coli) patients and in sporadic colorectal tumors. Tohoku J Exp Med. 1992; 168:141-147. https://doi.org/ PubMed.1620/tjem.168.141 [PubMed].

7. Novellasdemunt L, Antas P, Li VS. Targeting Wnt signaling in colorectal cancer. A Review in the Theme: Cell Signaling: Proteins, Pathways and Mechanisms. Am J Physiol Cell Physiol. 2015; 309:C511-521. https://doi.org/10.1152/ajpcell.00117.2015 [PubMed].

8. Rowan AJ, Lamlum H, Ilyas M, Wheeler J, Straub J, Papadopoulou A, Bicknell D, Bodmer WF, Tomlinson IP. APC mutations in sporadic colorectal tumors: A mutational "hotspot" and interdependence of the "two hits". Proc Natl Acad Sci U S A. 2000; 97:3352-3357. https://doi. org/10.1073/pnas.97.7.3352 [PubMed].

9. Cruz-Correa M, Hylind LM, Romans KE, Booker SV, Giardiello FM. Long-term treatment with sulindac in familial adenomatous polyposis: a prospective cohort study. Gastroenterology. 2002; 122:641-645. https://doi. org/10.1053/gast.2002.31890 [PubMed].

10. Keller JJ, Offerhaus GJ, Drillenburg P, Caspers E, Musler A, Ristimaki A, Giardiello FM. Molecular analysis of sulindacresistant adenomas in familial adenomatous polyposis. Clin Cancer Res. 2001; 7:4000-4007. https://doi.org/10.1016/ S0016-5085(08)81489-8 [PubMed].

11. Lynch PM. Chemoprevention of familial adenomatous polyposis. Fam Cancer. 2016; 15:467-475. https://doi. org/10.1007/s10689-016-9901-9 [PubMed].

12. Matsuhashi N, Nakajima A, Fukushima Y, Yazaki Y, Oka T. Effects of sulindac on sporadic colorectal adenomatous polyps. Gut. 1997; 40:344-349. https://doi.org/10.1136/ gut.40.3.344 [PubMed].

13. Septer S, Lawson CE, Anant S, Attard T. Familial adenomatous polyposis in pediatrics: natural history, emerging surveillance and management protocols, chemopreventive strategies, and areas of ongoing debate. Fam Cancer. 2016; 15:477-485. https://doi.org/10.1007/ s10689-016-9905-5 [PubMed].

14. Wakeman C, Keenan J, Eteuati J, Hollington P, Eglinton T, Frizelle F. Chemoprevention of colorectal neoplasia ANZ J Surg. 2015; 87:E228-E232. https://doi.org/10.1111/ ans.13392 [PubMed].

15. Warrier SK, Kalady MF. Familial adenomatous polyposis: challenges and pitfalls of surgical treatment. Clin Colon Rectal Surg. 2012; 25:83-89. https://doi. org/10.1055/s-0032-1313778 [PubMed].

16. Yeung AT, Patel BB, Li XM, Seeholzer SH, Coudry RA, Cooper HS, Bellacosa A, Boman BM, Zhang T, Litwin S, Ross EA, Conrad P, Crowell JA, et al. One-hit effects in cancer: altered proteome of morphologically normal colon crypts in familial adenomatous polyposis. Cancer Res. 2008; 68:7579-7586. https://doi.org/10.1158/0008-5472. CAN-08-0856 [PubMed].

17. Holdorf MM, Owen HA, Lieber SR, Yuan L, Adams N, Dabney-Smith C, Makaroff CA. Arabidopsis ETHE1 encodes a sulfur dioxygenase that is essential for embryo and endosperm development. Plant Physiol. 2012; 160:226236. https://doi.org/10.1104/pp.112.201855 [PubMed].

18. Hildebrandt TM, Di Meo I, Zeviani M, Viscomi C, Braun HP. Proteome adaptations in Ethe1-deficient mice indicate a role in lipid catabolism and cytoskeleton organization via post-translational protein modifications. Biosci Rep. 2013; 33. https://doi.org/10.1042/BSR20130051 [PubMed].

19. Vitvitsky V, Kabil O, Banerjee R. High turnover rates for hydrogen sulfide allow for rapid regulation of its tissue concentrations. Antioxid Redox Signal. 2012; 17:22-31. https://doi.org/10.1089/ars.2011.4310 [PubMed].

20. Henriques BJ, Lucas TG, Rodrigues JV, Frederiksen JH, Teixeira MS, Tiranti V, Bross P, Gomes CM. Ethylmalonic encephalopathy ETHE1 R163W/R163Q mutations alter protein stability and redox properties of the iron centre. PLoS One. 2014; 9:e107157. https://doi.org/10.1371/journal.pone.0107157 [PubMed]. 
21. Kabil O, Banerjee R. Characterization of patient mutations in human persulfide dioxygenase (ETHE1) involved in $\mathrm{H} 2 \mathrm{~S}$ catabolism. J Biol Chem. 2012; 287:44561-44567. https:// doi.org/10.1074/jbc.M112.407411 [PubMed].

22. Tiranti V, D'Adamo P, Briem E, Ferrari G, Mineri R, Lamantea E, Mandel H, Balestri P, Garcia-Silva MT, Vollmer B, Rinaldo P, Hahn SH, Leonard J, et al. Ethylmalonic encephalopathy is caused by mutations in ETHE1, a gene encoding a mitochondrial matrix protein. Am J Hum Genet. 2004; 74:239-252. https://doi. org/10.1086/381653 [PubMed].

23. Tiranti V, Viscomi C, Hildebrandt T, Di Meo I, Mineri R, Tiveron C, Levitt MD, Prelle A, Fagiolari G, Rimoldi M, Zeviani M. Loss of ETHE1, a mitochondrial dioxygenase, causes fatal sulfide toxicity in ethylmalonic encephalopathy. Nat Med. 2009; 15:200-205. https://doi.org/10.1038/ nm.1907 [PubMed].

24. Modis K, Bos EM, Calzia E, van Goor H, Coletta C, Papapetropoulos A, Hellmich MR, Radermacher P, Bouillaud F, Szabo C. Regulation of mitochondrial bioenergetic function by hydrogen sulfide. Part II. Pathophysiological and therapeutic aspects. Br J Pharmacol. 2014; 171:2123-2146. https://doi.org/10.1111/bph.12368 [PubMed].

25. Lagoutte E, Mimoun S, Andriamihaja M, Chaumontet C, Blachier F, Bouillau d F. Oxidation of hydrogen sulfide remains a priority in mammalian cells and causes reverse electron transfer in colonocytes. Biochim Biophys Acta. 2010; 1797:1500-1511. https://doi.org/10.1016/j. bbabio.2010.04.004 [PubMed].

26. Szabo C, Coletta C, Chao C, Modis K, Szczesny B, Papapetropoulos A, Hellmich MR. Tumor-derived hydrogen sulfide, produced by cystathionine-beta-synthase, stimulates bioenergetics, cell proliferation, and angiogenesis in colon cancer. Proc Natl Acad Sci U S A. 2013; 110:12474-12479. https://doi.org/10.1073/pnas.1306241110 [PubMed].

27. Ruderman NB, Xu XJ, Nelson L, Cacicedo JM, Saha AK, Lan F, Ido Y. AMPK and SIRT1: a long-standing partnership? Am J Physiol Endocrinol Metab. 2010; 298:E751-760. https://doi.org/10.1152/ajpendo.00745.2009 [PubMed].

28. Li X. SIRT1 and energy metabolism. Acta Biochim Biophys Sin (Shanghai). 2013; 45:51-60. https://doi.org/10.1093/ abbs/gms 108 [PubMed].

29. Gillum MP, Erion DM, Shulman GI. Sirtuin-1 regulation of mammalian metabolism. Trends Mol Med. 2011; 17:8-13. https://doi.org/10.1016/j.molmed.2010.09.005 [PubMed].

30. Cerutti R, Pirinen E, Lamperti C, Marchet S, Sauve AA, Li W, Leoni V, Schon EA, Dantzer F, Auwerx J, Viscomi C, Zeviani M. NAD $(+)$-dependent activation of Sirt1 corrects the phenotype in a mouse model of mitochondrial disease. Cell Metab. 2014; 19:1042-1049. https://doi.org/10.1016/j. cmet.2014.04.001 [PubMed].

31. Hardie DG, Ross FA, Hawley SA. AMPK: a nutrient and energy sensor that maintains energy homeostasis. Nat Rev
Mol Cell Biol. 2012; 13:251-262. https://doi.org/10.1038/ nrm3311 [PubMed].

32. Canto C, Auwerx J. PGC-1alpha, SIRT1 and AMPK, an energy sensing network that controls energy expenditure. Curr Opin Lipidol. 2009; 20:98-105. https://doi. org/10.1097/MOL.0b013e328328d0a4 [PubMed].

33. Fernandez-Marcos PJ, Auwerx J. Regulation of PGC1 alpha, a nodal regulator of mitochondrial biogenesis. Am J Clin Nutr. 2011; 93:884S-890. https://doi.org/10.3945/ ajcn.110.001917 [PubMed].

34. Mihaylova MM, Shaw RJ. The AMPK signalling pathway coordinates cell growth, autophagy and metabolism. Nat Cell Biol. 2011; 13:1016-1023. https://doi.org/10.1038/ ncb2329 [PubMed].

35. Lu C, Kavalier A, Lukyanov E, Gross SS. S-sulfhydration/ desulfhydration and S-nitrosylation/denitrosylation: a common paradigm for gasotransmitter signaling by $\mathrm{H} 2 \mathrm{~S}$ and NO. Methods. 2013; 62:177-181. https://doi.org/10.1016/j. ymeth.2013.05.020 [PubMed].

36. Miranda KM, Wink DA. Persulfides and the cellular thiol landscape. Proc Natl Acad Sci U S A. 2014; 111:7505-7506. https://doi.org/10.1073/pnas.1405665111 [PubMed].

37. Pettinati I, Brem J, Lee SY, McHugh PJ, Schofield CJ. The Chemical Biology of Human Metallo-beta-Lactamase Fold Proteins. Trends Biochem Sci. 2016; 41:338-355. https:// doi.org/10.1016/j.tibs.2015.12.007 [PubMed].

38. Pettinati I, Brem J, McDonough MA, Schofield CJ. Crystal structure of human persulfide dioxygenase: structural basis of ethylmalonic encephalopathy. Hum Mol Genet. 2015; 24:2458-2469. https://doi.org/10.1093/hmg/ddv007 [PubMed].

39. Chekulayev V, Mado K, Shevchuk I, Koit A, Kaldma A, Klepinin A, Timohhina N, Tepp K, Kandashvili M, Ounpuu L, Heck K, Truu L, Planken A, et al. Metabolic remodeling in human colorectal cancer and surrounding tissues: alterations in regulation of mitochondrial respiration and metabolic fluxes. Biochemistry and Biophysics Reports. 2015; 4:111-125. https://doi.org/10.1016/j. bbrep.2015.08.020 [PubMed].

40. Ward PS, Thompson CB. Metabolic reprogramming: a cancer hallmark even warburg did not anticipate. Cancer Cell. 2012; 21:297-308. https://doi.org/10.1016/j. ccr.2012.02.014 [PubMed].

41. Houtkooper RH, Pirinen E, Auwerx J. Sirtuins as regulators of metabolism and healthspan. Nat Rev Mol Cell Biol. 2012; 13:225-238. $\quad$ https://doi.org/10.1038/nrm3293 [PubMed].

42. Austin S, St-Pierre J. PGC1alpha and mitochondrial metabolism--emerging concepts and relevance in ageing and neurodegenerative disorders. J Cell Sci. 2012; 125:49634971. https://doi.org/10.1242/jcs.113662 [PubMed].

43. Canto C, Gerhart-Hines Z, Feige JN, Lagouge M, Noriega L, Milne JC, Elliott PJ, Puigserver P, Auwerx J. AMPK regulates energy expenditure by modulating NAD + metabolism and SIRT1 activity. Nature. 2009; 
458:1056-1060. htps://doi.org/10.1038/nature07813 [PubMed].

44. Toyama EQ, Herzig S, Courchet J, Lewis TL Jr, Loson OC, Hellberg K, Young NP, Chen H, Polleux F, Chan DC, Shaw RJ. Metabolism. AMP-activated protein kinase mediates mitochondrial fission in response to energy stress. Science. 2016; 351:275-281. https://doi.org/10.1126/science.aab4138 [PubMed].

45. Renga B. Hydrogen sulfide generation in mammals: the molecular biology of cystathionine-beta- synthase (CBS) and cystathionine-gamma-lyase (CSE). Inflamm Allergy Drug Targets. 2011; 10:85-91 _ https://doi. org/10.2174/187152811794776286

46. Saint-Geniez M, Jiang A, Abend S, Liu L, Sweigard H, Connor KM, Arany Z. PGC-1alpha regulates normal and pathological angiogenesis in the retina. Am J Pathol. 2013; 182:255-265. https://doi.org/10.1016/j.ajpath.2012.09.003 [PubMed].

47. Shin SW, Yun SH, Park ES, Jeong JS, Kwak JY, Park JI. Overexpression of PGC1alpha enhances cell proliferation and tumorigenesis of HEK293 cells through the upregulation of $\mathrm{Sp} 1$ and Acyl-CoA binding protein. Int J Oncol. 2015; 46:1328-1342. https://doi.org/10.3892/ ijo.2015.2834 [PubMed].

48. Di Meo I, Lamperti C, Tiranti V. Mitochondrial diseases caused by toxic compound accumulation: from etiopathology to therapeutic approaches. EMBO Mol Med. 2015; 7:1257-1266. https://doi.org/10.15252/ emmm.201505040 [PubMed].

49. Sahebekhtiari N, Thomsen MM, Sloth JJ, Stenbroen V, Zeviani M, Gregersen N, Viscomi C, Palmfeldt J. Quantitative proteomics suggests metabolic reprogramming during ETHE1 deficiency. Proteomics. 2016; 16:1166-1176. https://doi.org/10.1002/pmic.201500336 [PubMed].

50. Higashitsuji H, Higashitsuji H, Nagao T, Nonoguchi K, Fujii S, Itoh K, Fujita J. A novel protein overexpressed in hepatoma accelerates export of NF-kappa B from the nucleus and inhibits p53-dependent apoptosis. Cancer Cell. 2002; 2:335-346. https://doi.org/10.1016/S15356108(02)00152-6 [PubMed].

51. Ganapathy-Kanniappan S. Molecular intricacies of aerobic glycolysis in cancer: current insights into the classic metabolic phenotype. Crit Rev Biochem Mol Biol. 2018; 53:667-682. https://doi.org/10.1080/10409238.2018.15565 78 [PubMed].
52. Orang AV, Petersen J, McKinnon RA, Michael MZ. Micromanaging aerobic respiration and glycolysis in cancer cells Mol Metab. 2019; 23:98-126. https://doi.org/10.1016/j. molmet.2019.01.014 [PubMed].

53. Prusinkiewicz MA, Mymryk JS. Metabolic Reprogramming of the Host Cell by Human Adenovirus Infection. Viruses. 2019; 11. https://doi.org/10.3390/v11020141 [PubMed].

54. Castellarin M, Warren RL, Freeman JD, Dreolini L, Krzywinski M, Strauss J, Barnes R, Watson P, Allen-Vercoe E, Moore RA, Holt RA. Fusobacterium nucleatum infection is prevalent in human colorectal carcinoma. Genome Res. 2012; 22:299-306. https://doi.org/10.1101/gr.126516.111 [PubMed].

55. Kostic AD, Gevers D, Pedamallu CS, Michaud M, Duke F, Earl AM, Ojesina AI, Jung J, Bass AJ, Tabernero J, Baselga J, Liu C, Shivdasani RA, et al. Genomic analysis identifies association of Fusobacterium with colorectal carcinoma. Genome Res. 2012; 22:292-298. https://doi.org/10.1101/ gr.126573.111 [PubMed].

56. Gur C, Ibrahim Y, Isaacson B, Yamin R, Abed J, Gamliel M, Enk J, Bar-On Y, Stanietsky-Kaynan N, CoppenhagenGlazer S, Shussman N, Almogy G, Cuapio A, et al. Binding of the Fap2 protein of Fusobacterium nucleatum to human inhibitory receptor TIGIT protects tumors from immune cell attack. Immunity. 2015; 42:344-355. https://doi. org/10.1016/j.immuni.2015.01.010 [PubMed].

57. Ye X, Wang R, Bhattacharya R, Boulbes DR, Fan F, Xia L, Adoni H, Ajami NJ, Wong MC, Smith DP, Petrosino JF, Venable S, Qiao W, et al. Fusobacterium Nucleatum Subspecies Animalis Influences Proinflammatory Cytokine Expression and Monocyte Activation in Human Colorectal Tumors. Cancer Prev Res (Phila). 2017; 10:398-409. https:// doi.org/10.1158/1940-6207.CAPR-16-0178 [PubMed].

58. Bettegowda C, Sausen M, Leary RJ, Kinde I, Wang Y, Agrawal N, Bartlett BR, Wang H, Luber B, Alani RM, Antonarakis ES, Azad NS, Bardelli A, et al. Detection of circulating tumor DNA in early- and late-stage human malignancies. Sci Transl Med. 2014; 6:224ra224 https://doi. org/10.1126/scitranslmed.3007094. [PubMed].

59. Witherspoon M, Chen Q, Kopelovich L, Gross SS, Lipkin SM. Unbiased metabolite profiling indicates that a diminished thymidine pool is the underlying mechanism of colon cancer chemoprevention by alphadifluoromethylornithine. Cancer Discov. 2013; 3:10721081. https://doi.org/10.1158/2159-8290.CD-12-0305 [PubMed]. 